\title{
INCIDÊNCIA DOS SINTOMAS OSTEOMUSCULARES EM FOTÓGRAFOS DA CIDADE DE TERESINA-PI
}

\author{
Diego Rodrigues Pessoa ${ }^{1}$ \\ Diego Pereira Barros ${ }^{2}$ \\ Lívia Danyelle Viana Lima ${ }^{3}$ \\ Rosana Maria Nogueira Gonçalves Soares ${ }^{4}$ \\ Janaína de Moraes Silva ${ }^{5}$
}

Resumo: Lesões por Esforços Repetitivos ou Doenças Osteomusculares Relacionadas ao Trabalho (LER/DORT), são definidas como um conjunto de afecções que podem acometer tendões, sinóvias, músculos, nervos, fáscias, ligamentos, entre outras. O objetivo do estudo foi investigar a incidência de queixas osteomusculares. A pesquisa trata-se de um estudo observacional de corte transversal com abordagem qualitativa, com 16 fotógrafos do sexo masculino, que foram investidos por meio do diagrama de Corllett. As regiões mais acometidas foram à região das costas-médias (81,25\%), em seguida a perna (75\%), punhos (56,25\%), região cervical, coluna lombar, ombro e pescoço $(43,75 \%)$, a região das costassuperiores e na bacia com (37,5\%), respectivamente. O estudo demonstrou elevada ocorrência de sintomatologia na região das costas-médias em indivíduos jovens adultos, onde os fatores de risco presentes são fatores predominantes para o surgimento das LER/DORT na população.

Palavras-chave: Lesões por esforços repetitivos; Distúrbios osteomusculares relacionados ao trabalho; Fotógrafo profissional.

\footnotetext{
1 Universidade do Vale do Paraíba (UNIVAP), Centro de Laserterapia e Fotobiologia - CELAFO, Instituto de Pesquisa e Desenvolvimento, Av. Shishima Hifumi, 2911, Urbanova, São José dos Campos, SP, Brasil. E-mail: fisio.diegorodrigues@gmail.com.

2 Bacharelado em Fisioterapia, Brasil. E-mail: dpbarros@hotmail.com.

3 Bacharelado em Fisioterapia/Faculdade Maurício de Nassau, Brasil. E-mail: livia_danielly@hotmail.com.

${ }^{4}$ Bacharelado em Fisioterapia/Faculdade Santo Agostinho (FSA), Brasil. E-mail: rosanameireles25@gmail.com.

${ }^{5}$ Centro de Ciências da Saúde- CCS/Universidade Estadual do Piauí, Brasil. E-mail: fisiojanainams@gmail.com.
} 